\title{
THE
}

$1-19-2018$

\section{Reduction Reactions of Electrolyte Salts for Lithium Ion Batteries: LiPF6, LiBF4, LiDFOB, LiBOB, and LiTFSI}

\author{
Bharathy S. Parimalam \\ University of Rhode Island \\ Brett L. Lucht \\ University of Rhode Island, blucht@uri.edu
}

Follow this and additional works at: https://digitalcommons.uri.edu/chm_facpubs

Creative Commons License

\section{(c) (†)}

This work is licensed under a Creative Commons Attribution 4.0 License.

\section{Citation/Publisher Attribution}

Parimalam, B. S., \& Lucht, B. L. (2018). Reduction Reactions of Electrolyte Salts for Lithium lon Batteries: LiPF6, LiBF4, LiDFOB, LiBOB, and LiTFSI. Journal of the Electrochemical Society, 165, A251-A255. doi: 10.1149/2.0901802jes

Available at: http://dx.doi.org/10.1149/2.0901802jes

This Article is brought to you for free and open access by the Chemistry at DigitalCommons@URI. It has been accepted for inclusion in Chemistry Faculty Publications by an authorized administrator of DigitalCommons@URI. For more information, please contact digitalcommons-group@uri.edu. 


\title{
Reduction Reactions of Electrolyte Salts for Lithium Ion Batteries: $\mathrm{LiPF}_{6}, \mathrm{LiBF}_{4}$, LiDFOB, LiBOB, and LiTFSI
}

\author{
Bharathy S. Parimalam and Brett L. Lucht $\oplus^{*, z}$ \\ Department of Chemistry, University of Rhode Island, Kingston, Rhode Island 02881, USA
}

\begin{abstract}
The reduction products of common lithium salts for lithium ion battery electrolytes, $\mathrm{LiPF}_{6}, \mathrm{LiBF}_{4}$, lithium bisoxalato borate (LiBOB), lithium difluorooxalato borate (LiDFOB), and lithium trifluorosulfonylimide (LiTFSI), have been investigated. The solution phase reduction of different lithium salts via reaction with the one electron reducing agent, lithium naphthalenide, results in near quantitative reactions. Analysis of the solution phase and head space gasses suggests that all of the reduction products are precipitated as insoluble solids. The solids obtained through reduction were analyzed with solution NMR, IR-ATR and XPS. All fluorine containing salts generate $\mathrm{LiF}$ upon reduction while all oxalate containing salts generate lithium oxalate. In addition, depending upon the salt other species including, $\mathrm{Li}_{\mathrm{x}} \mathrm{PF}_{\mathrm{y}} \mathrm{O}_{\mathrm{z}}, \mathrm{Li}_{\mathrm{x}} \mathrm{BF}_{\mathrm{y}}$, oligomeric borates, and lithium bis[N-(trifluoromethylsulfonylimino)] trifluoromethanesulfonate are observed.

(c) The Author(s) 2018. Published by ECS. This is an open access article distributed under the terms of the Creative Commons Attribution 4.0 License (CC BY, http://creativecommons.org/licenses/by/4.0/), which permits unrestricted reuse of the work in any medium, provided the original work is properly cited. [DOI: 10.1149/2.0901802jes]

(cc) BY
\end{abstract}

Manuscript submitted December 7, 2017; revised manuscript received January 4, 2018. Published January 19, 2018.

A typical lithium-ion battery contains a graphite anode, a lithiated transition metal oxide cathode, and an electrolyte solution composed of inorganic lithium salts dissolved in a mixture of organic carbonate solvents which frequently includes electrolyte additives. ${ }^{1}$ The longterm cyclability of the lithium-ion battery is dependent upon the anode solid electrolyte interphase (SEI), formed due to the electrochemical reduction of the electrolyte solution. ${ }^{2}$ Understanding the mechanisms of the reduction reactions along with the products of the reactions is essential for the development of better lithium-ion batteries. The SEI has been proposed to contain lithium alkyl carbonates, lithium carbonate, lithium oxalate, lithium alkoxides, and lithium oxide from the carbonate solvents and LiF, lithium fluorophosphates, lithium fluoroborates, and lithium oxalate from the reduction of electrolyte salts, depending upon the salt utilitzed. ${ }^{3-21}$ Electrolyte additives have also been used to tailor the properties of the SEI through preferential reduction on anode. ${ }^{1}$ Despite significant effort over the last two decades, the formation mechanism of the SEI is not well understood. One difficulty in understanding the composition of the SEI is that the SEI is a complicated mixture of compounds, which results from multiple simultaneous and competing reduction reactions. In addition, since the SEI is very thin $(\sim 50 \mathrm{~nm})$ and unstable in the presence of oxygen or water, characterization is very difficult. We have reported a detailed analysis of binder free graphitic anodes cycled in simplified electrolytes which suggest that the initial reduction reaction of the carbonates generate lithium alkyl carbonates and $\mathrm{LiF}$ as the predominant components of the anode SEI. ${ }^{20,21}$ Synthesis of initial SEI components from carbonate solvents in high yield through reduction of the solvents with lithium naphthalenide has been reported. The unique advantage of this reduction technique is the generation and isolation of SEI constituents from individual electrolyte components in high yield without competing reduction reactions. Reduction of ethylene carbonate results in generation of lithium ethylene dicarbonate and ethylene, while the reduction of dialkyl carbonates result in lithium alkyl carbonates and alkanes. ${ }^{22}$ As an expansion of these investigations, the reduction of some of the most common electrolyte salts with lithium naphthalenide has been investigated. All reduction reactions result in precipitation. The precipitates have been analyzed by solution Nuclear Magnetic Resonance (NMR) Spectroscopy, solid-state InfraRed spectroscopy with Attenuated Total Reflectance (IR-ATR) and $\mathrm{X}$-ray Photoelectron Spectroscopy (XPS). The results provide insight into the formation mechanism of the anode SEI.

*Electrochemical Society Member.

${ }^{\text {zE}}$-mail: blucht@chm.uri.edu

\section{Experimental}

Battery-grade lithium hexafluorophosphate $\left(\mathrm{LiPF}_{6}\right)$, lithium tetrafluoroborate $\left(\mathrm{LiBF}_{4}\right)$, lithium bis(oxalato)borate (Li$\mathrm{BOB}$ ), lithium difluoro(oxalato)borate (LiDFOB), and lithium bis(trifluoromethylsulfonyl)imide (LiTFSI) (Figure 1) were obtained from BASF. Diethyl ether $\left(\mathrm{Et}_{2} \mathrm{O}\right)$, tetrahydrofuran (THF), and naphthalene were purchased from Sigma-Aldrich. Lithium discs were obtained from MTI Corporation. All the reagents were stored in an argon filled glove box at room temperature and used without further purification. Lithium naphthalenide solution (Li[NAP]) in THF or $\mathrm{Et}_{2} \mathrm{O}$ was prepared with $10 \mathrm{~mol} \%$ excess naphthalene. Ethereal solvents were used since the solvents do not react with Li[NAP]. The solvent is not expected to significantly alter the reduction products of the salts. Lithium foils were added to naphthalene solution of either $\mathrm{THF}$ or $\mathrm{Et}_{2} \mathrm{O}$ and stirred for 3 days at room temperature. The solution turned green or purple, respectively, in a few minutes after the addition of lithium metal and became darkly colored after stirring for 3 days, as previously reported. ${ }^{23}$

Number of equivalents of reducing agent required for the complete reduction of electrolyte salts was evaluated by NMR analysis. Electrolyte salts were dissolved in either THF or $\mathrm{Et}_{2} \mathrm{O}$ and reacted with different molar equivalents of $\mathrm{Li}[\mathrm{NAP}]$, a one electron reducing agent, at room temperature overnight. The resulting reaction mixtures were transferred into clean dry NMR tubes along with a capillary tube filled with deuterated DMSO and an internal standard. The internal standards, LiTFSI; hexafluoro benzene; or $\mathrm{LiBF}_{4}$, were chosen carefully to avoid any overlapping peaks with the starting materials or products. The samples were analyzed with ${ }^{19} \mathrm{~F}$ and ${ }^{11} \mathrm{~B}$ NMR spectroscopy and the concentrations of the unreacted electrolyte salts were estimated in reference to the internal standard.

Electrolyte salts $\left(\mathrm{LiPF}_{6}, \mathrm{LiBF}_{4}, \mathrm{LiBOB}, \mathrm{LiDFOB}, \& \mathrm{LiTFSI}\right)$ were dissolved in $\mathrm{Et}_{2} \mathrm{O}$ and reduced with appropriate molar equivalents of Li[NAP] in larger scale. The evolved gasses and volatiles in the reaction mixtures were analyzed with GC-MS. The solid residues were washed with $\mathrm{Et}_{2} \mathrm{O}$ three times, dried overnight at room temperature, and analyzed with IR-ATR, solution NMR and XPS. All the reactions were conducted inside a nitrogen filled glovebox. XPS and IR-ATR analyses were conducted with no exposure to air. NMR, GC-MS were conducted with minimal exposure to air.

GC-MS analyses were conducted on an Agilent 6890-5973N GC equipped with an G973N mass selective detector. Liquid samples were diluted with dichloromethane, mixed with distilled water to remove the residual electrolyte salts and non-volatile inorganic components, and the organic phases were utilized for the analyses. Helium was used as carrier gas at a flow rate of $24 \mathrm{~mL} / \mathrm{min}$. The initial column temperature was $40^{\circ} \mathrm{C}$ and the temperature was ramped at $10^{\circ} \mathrm{C} / \mathrm{min}$ to $200^{\circ} \mathrm{C}$ and held at that temperature for 2 minutes with the total 


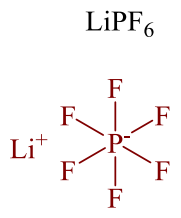

$\mathrm{FiBF}_{4} \mathrm{Li}^{+}$

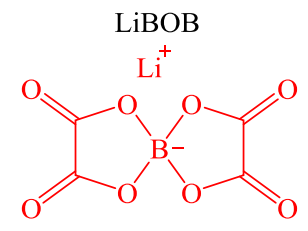

LiDFOB
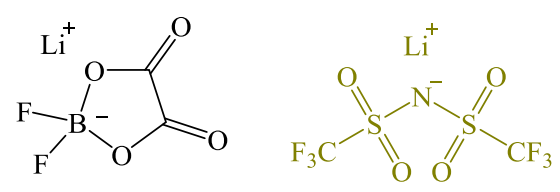

Figure 1. Structures of the electrolyte salts.

run time of 18 minutes. The mass spectra obtained were compared to the NIST library to determine their molecular structures. THF, $\mathrm{Et}_{2} \mathrm{O}$ (solvents) and naphthalene (starting material) and were the only volatile components present in the reaction mixtures. The gas analyses were performed by sampling the head spaces of the reaction mixtures in RB flasks with a $10 \mu \mathrm{L} \mathrm{GC}$ syringe. Helium was used as the carrier gas at a flow rate of $1.5 \mathrm{~mL} / \mathrm{min}$. The initial column temperature was set to $40^{\circ} \mathrm{C}$, and the temperature was ramped at $1^{\circ} \mathrm{C} / \mathrm{min}$ to $43^{\circ} \mathrm{C}$ and held at that temperature for $2 \mathrm{~min}$ with the total run time of 5 min. The mass spectra obtained were compared to the NIST library to determine their molecular structures.

IR-ATR spectra of the dried solid residues were acquired on a Bruker Tensor 27 spectrometer equipped with a germanium crystal in attenuated total reflectance (IR-ATR) mode. Samples were transferred using air-tight vials and the spectrometer was operated inside a nitrogen filled glovebox to avoid air exposure. Each spectrum was acquired with 128 scans from $700 \mathrm{~cm}^{-1}$ to $4000 \mathrm{~cm}^{-1}$ at the spectral resolution of $4 \mathrm{~cm}^{-1}$. The data were processed and analyzed using the OPUS and Originlab software.

NMR spectra of the samples were collected with a Bruker Avance III $300 \mathrm{MHz}$ NMR spectrometer at room temperature. The solids were dissolved in $\mathrm{D}_{2} \mathrm{O}$ in the nitrogen filled glovebox and ${ }^{19} \mathrm{~F},{ }^{31} \mathrm{P}$, ${ }^{11} \mathrm{~B}, \&{ }^{13} \mathrm{C}$ NMR spectra of the solutions were acquired. ${ }^{19} \mathrm{~F}$ NMR spectra are referenced to $\mathrm{LiF}$ at $-122.0 \mathrm{ppm}$, and ${ }^{11} \mathrm{~B}$ NMR spectra are referenced to residual salts: $\mathrm{LiBF}_{4}, \mathrm{LiBOB}$, or LiDFOB at $-1.5,7.4$, or $2.9 \mathrm{ppm}$, respectively. The spectra were processed and analyzed using MestReNova 10.0.2.

XPS spectra of the dried precipitates were acquired using a Thermo Scientific K-alpha XPS. Samples were made into circular pellets with a press or stuck on a conductive carbon tape as a thin layer and transferred from the glovebox to the XPS chamber using a vacuum transfer module without exposure to air. An argon flood gun was used to avoid surface charge accumulation during sample analysis. The binding energy was corrected based on the $\mathrm{C} 1 \mathrm{~s}$ of hydrocarbon at $284.8 \mathrm{eV}$. The data were processed and analyzed using the Thermo Avantage, XPS Peak 4.1 and the Originlab software.

\section{Results and Discussion}

Reduction of electrolyte salts.-The number of electrons required for the complete reduction of electrolyte salts was investigated by NMR analysis. Electrolyte salts dissolved in either THF or $\mathrm{Et}_{2} \mathrm{O}$ were reduced with different molar equivalents of $\mathrm{Li}[\mathrm{NAP}]$ at room temperature overnight. Addition of one molar equivalent of Li[NAP] to LiBOB, LiDFOB and LiTFSI solutions results in immediate discoloration of $\mathrm{Li}[\mathrm{NAP}]$ and precipitation of solid products, however discoloration in $\mathrm{LiPF}_{6}$ and $\mathrm{LiBF}_{4}$ samples takes roughly an hour, the color change is due to the consumption of Li[NAP] in the reduction of the electrolyte salts. Upon incorporation of higher concentrations of Li[NAP], > 1 molar equivalent, similar discoloration is observed. However, for samples where color retention is observed for more than 24 hours, the quantity of $\mathrm{Li}[\mathrm{NAP}]$ required to completely reduce the salt has been exceeded, thus allowing determination of the approximate number of equivalents of reducing agent. The reaction mixtures were transferred into NMR tubes and a capillary, filled DMSO- $\mathrm{d}_{6}$ and an internal standard, was added into each tube. The samples were analyzed with ${ }^{19} \mathrm{~F}$ and ${ }^{11} \mathrm{~B}$ NMR spectroscopy and the concentration of the remaining electrolyte salts were determined via integration of the NMR peaks compared to the internal standard, hexafluoro benzene or $\mathrm{LiBF}_{4}$. Reduction of $\mathrm{LiBF}_{4}$ with 1,2 , and 3 equivalents of $\mathrm{Li}[\mathrm{NAP}]$ results in consumption of approximately 40,69 , and $96 \pm 4 \%$ of the $\mathrm{LiBF}_{4}$, respectively, suggesting $3 \mathrm{e}^{-}$are required for quantitative reduction. Similarly, numbers of equivalents of Li[NAP] required for the reduction of $\mathrm{LiBOB}, \mathrm{LiDFOB}$, and LiTFSI were estimated to be $2 \mathrm{e}^{-}$, $2 \mathrm{e}^{-}$, and $12 \mathrm{e}^{-}$, respectively. The number of equivalents of Li[NAP] required for complete reduction of $\mathrm{LiPF}_{6}$ could not be measured reliably by NMR spectroscopy. However, in all cases low concentrations of residual salt are observed after the reduction reactions and some of the reduction products may precipitate prior to complete reduction, so the number of electrons required for reduction of the different salts should be viewed as approximate.

The electrolyte salts were then treated with a sufficient quantity of Li[NAP] to fully reduce the salt. All reactions result in a significant quantity of precipitate. The remaining solution was analyzed by GC-MS and NMR spectroscopy. The only component remaining in solution is a low concentration of the unreacted salt. In addition, analysis of the headspace of the samples detected no gaseous products resulting from the reduction reactions. The results suggest that all of the reduction products of the lithium salts are insoluble. Thus, the $\mathrm{Li}[\mathrm{NAP}]$ reduction of all lithium salts investigated results in quantitative conversion to organic solvent insoluble components.

NMR analysis of the solids.-The residual organic solvent insoluble solids have been analyzed via a combination of solution NMR spectroscopy in $\mathrm{D}_{2} \mathrm{O}$, Infrared spectroscopy with attenuated total reflectance (IR-ATR), and X-ray photo electron spectroscopy (XPS). The residual solids have been dissolved in $\mathrm{D}_{2} \mathrm{O}$ for NMR analysis. While most of the residual solids dissolve in $\mathrm{D}_{2} \mathrm{O}$, some of the solid does not readily dissolve. In addition, some of the reduction products may react with water to generate subsequent hydrolysis products. The dissolved solids were analyzed via a combination of ${ }^{11} \mathrm{~B},{ }^{13} \mathrm{C},{ }^{19} \mathrm{~F}$, and ${ }^{31}$ P NMR spectroscopy. Representative NMR spectra of the solids are provided in Figure 2.

The ${ }^{19} \mathrm{~F}$ NMR spectrum of the reduction product from $\mathrm{LiPF}_{6}$ displays a strong singlet corresponding to $\mathrm{LiF}$ at -122 and a medium singlet at $-128.5 \mathrm{ppm}$ corresponding to $\mathrm{HF}^{24}$ While LiF is a frequently reported as a product of the reduction of $\mathrm{LiPF}_{6}$, HF is most likely generated from the hydrolysis of unreacted $\mathrm{LiPF}_{6}$ in $\mathrm{D}_{2} \mathrm{O}$. In addition, a doublet is observed at $-81.3 \mathrm{ppm}$ in the ${ }^{19} \mathrm{~F}$ NMR spectrum which has a corresponding triplet at $-15.7 \mathrm{ppm}$ in the ${ }^{31} \mathrm{P}$ NMR spectrum and a coupling constant of $962 \mathrm{~Hz}$ characteristic of $\mathrm{LiPO}_{2} \mathrm{~F}_{2}$. The presence of $\mathrm{LiPO}_{2} \mathrm{~F}_{2}$ likely results from the hydrolysis of $\mathrm{LiPF}_{2}$ upon addition of the residual solid to $\mathrm{D}_{2} \mathrm{O}$, since no extractable oxygen is present in the reaction media. The XPS data, as discussed below, provides further support for this assignment.

The ${ }^{19} \mathrm{~F}$ NMR spectrum of the residual solids from the reduction of $\mathrm{LiBF}_{4}$ contains a strong singlet at $-122 \mathrm{ppm}$ characteristic of $\mathrm{LiF}$. In addition, the sample exhibits a weak set of peaks at $-149 \mathrm{ppm}$ in the ${ }^{19} \mathrm{~F}$ NMR spectrum characteristic of residual $\mathrm{LiBF}_{4}$. A single peak is observed in the ${ }^{11} \mathrm{~B}$ NMR spectrum peak at $-1.5 \mathrm{ppm}$ characteristic of residual $\mathrm{LiBF}_{4}$.

The ${ }^{13} \mathrm{C}$ NMR spectrum of the residual solids obtained from reduction of LiBOB displays a strong singlet at $173.2 \mathrm{ppm}$ characteristic of in lithium oxalate. The other peaks observed in the ${ }^{13} \mathrm{C}$ NMR spectra are characteristic of residual solvents, THF and $\mathrm{Et}_{2} \mathrm{O}$, used for the reduction reaction. The peaks at 67.8 and $25.0 \mathrm{ppm}$ are characteristic of residual THF while the peaks at 66.0 and $14.1 \mathrm{ppm}$ are characteristic of residual $\mathrm{Et}_{2} \mathrm{O}$. There are no peaks observed for residual $\mathrm{LiBOB}$ 


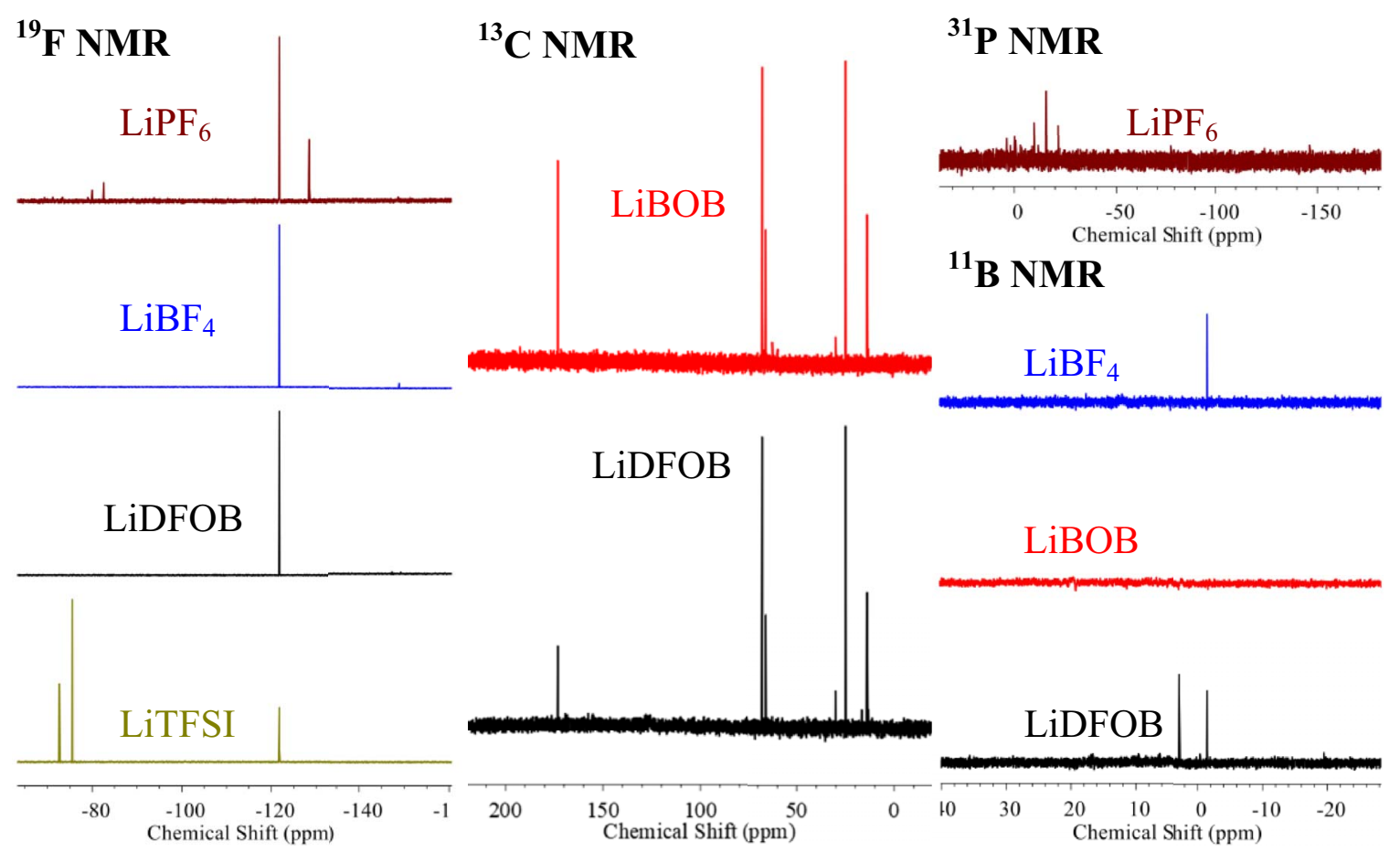

Figure 2. Solution NMR spectra of the solids from the Li[NAP] reduction of electrolyte salts.

in either the ${ }^{11} \mathrm{~B}$ or ${ }^{13} \mathrm{C}$ NMR spectra consistent with quantitative reduction of $\mathrm{LiBOB}$ under the reaction conditions.

The NMR spectrum of the residual solid from the reduction of LiDFOB is similar to a combination of the reduction products of $\mathrm{LiBF}_{4}$ and LiBOB. The ${ }^{19} \mathrm{~F}$ NMR spectrum is dominated by $\mathrm{LiF}$ at -122 ppm, but also contains small sets of peaks at -147 and $-149 \mathrm{ppm}$ characteristic of residual $\mathrm{LiDFOB}$ and $\mathrm{LiBF}_{4}$, respectively. The corresponding peaks characteristic of LiDFOB and $\mathrm{LiBF}_{4}$ are observed in the ${ }^{11} \mathrm{~B}$ NMR spectra at $2.9 \mathrm{ppm}$ and $-1.5 \mathrm{ppm}$, respectively. The ${ }^{13} \mathrm{C}$ NMR spectrum contains a strong peak at $173.2 \mathrm{ppm}$ characteristic of lithium oxalate, along with peaks characteristic of residual THF and $\mathrm{Et}_{2} \mathrm{O}$. However, unlike LiBOB some residual LiDFOB is observed at $161.1 \mathrm{ppm}$.

The ${ }^{19} \mathrm{~F}$ NMR spectrum of the solids from the reduction of LiTFSI shows a strong singlet corresponding to $\mathrm{LiF}$. In addition, two strong peaks at $-75.6 \mathrm{ppm}$ and $-72.7 \mathrm{ppm}$ with peak areas in $2: 1$ ratio. The peak integrations have a 2:1 ratio which is independent of the quantity of $\mathrm{Li}[\mathrm{NAP}]$ added suggesting that they arise from a single molecular species. The spectral data is consistent with the generation of lithium bis[N-(trifluoromethylsulfonylimino)] trifluoromethanesulfonate $\left(\mathrm{LiOS}\left(\mathrm{CF}_{3}\right)\left(\mathrm{NSO}_{2} \mathrm{CF}_{3}\right)_{2}\right.$ as previously reported. ${ }^{25}$ No residual LiTFSI is observed at $-79.4 \mathrm{ppm}$ in the ${ }^{19} \mathrm{~F}$ NMR spectrum.

FTIR analysis of the solids.-In an effort to further understand the composition of the solids obtained from reduction, the reduction products of the salts have been analyzed with IR-ATR. The IR-ATR spectra of the solids generated from the reduction of LiBOB and LiDFOB are provided in Figure 3. IR-ATR spectra of the residual solids for the other salts were also acquired, but the spectra were dominated by residual solvent and naphthalene since the decomposition products do not contain any functional groups which strongly absorb IR radiation, consistent with the observation of $\mathrm{LiF}$ as the predominant component by NMR.

The reduction product of $\mathrm{LiBOB}$ exhibits strong absorptions around 1670,1330 and $780 \mathrm{~cm}^{-1}$ characteristic of lithium oxalate. The peaks at 1805 and $1770 \mathrm{~cm}^{-1}$ are characteristic of $-\mathrm{CO}_{2}-\mathrm{B}-\mathrm{CO}_{2}$ oscillations and the peak at $1250 \mathrm{~cm}^{-1}$ corresponds to combination

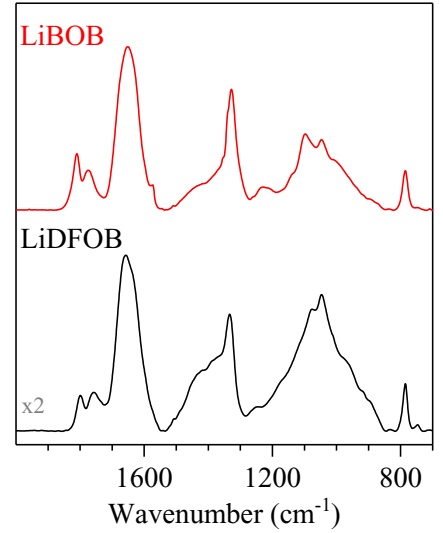

Figure 3. FTIR spectra of the solids from the Li[NAP] reduction of LiBOB and LiDFOB.

of O-C-C asymmetric stretching and O-B-O bending, suggesting the presence of a combination of LiBOB and crosslinked oligomeric borates, as previously reported. ${ }^{26,27} \mathrm{~A}$ weak broad absorption is also observed between 1400 and $1500 \mathrm{~cm}^{-1}$, consistent with the presence of $\mathrm{Li}_{2} \mathrm{CO}_{3}$. In addition to the reduction products, absorptions corresponding to residual THF at 1070 and $910 \mathrm{~cm}^{-1}$ are also observed. The reduction product of LiDFOB displays IR absorptions very similar to the solids from LiBOB consistent with the presence of lithium oxalate, crosslinked oligomeric borates, and $\mathrm{Li}_{2} \mathrm{CO}_{3}$, except the intensity of the broad absorption characteristic of $\mathrm{Li}_{2} \mathrm{CO}_{3}$ is increased.

X-ray photoelectron spectroscopy of the solids.-The solids generated from the reduction of $\mathrm{LiPF}_{6}$, and $\mathrm{LiBF}_{4}$ were analyzed with XPS and the spectra are displayed in Figure 4. XPS analysis of the other residual solids was attempted, but the insoluble reduction products contain residual solvent and naphthalene which cannot be removed which resulted in contamination of the XPS analysis chamber 

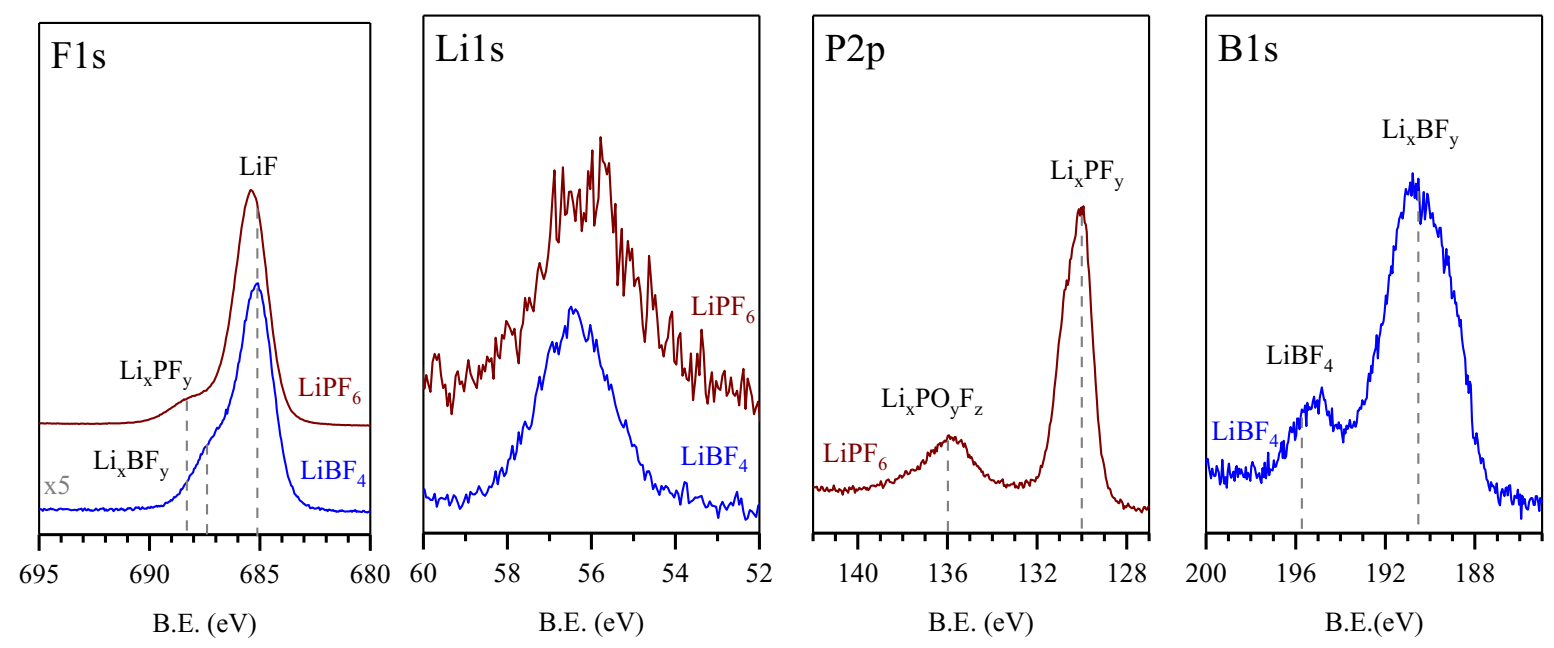

Figure 4. XPS spectra of the solids from the $\mathrm{Li}[\mathrm{NAP}]$ reduction of $\mathrm{LiPF}_{6}, \mathrm{LiBF}_{4}$, and LiTFSI.

for several months. Thus, we were unable to obtain XPS spectra of the other reduction products.

The F1s spectrum of the residual solid from the reduction of $\mathrm{LiPF}_{6}$ is dominated by a peak at $685 \mathrm{eV}$ characteristic of $\mathrm{LiF}$. The shoulder at $688.3 \mathrm{eV}$ is characteristic of $\mathrm{P}-\mathrm{F}$ species in $\mathrm{Li}_{\mathrm{x}} \mathrm{PF}_{\mathrm{y}}$ and $\mathrm{Li}_{\mathrm{x}} \mathrm{PF}_{\mathrm{y}} \mathrm{O}_{\mathrm{z}}$. The $\mathrm{P} 2 \mathrm{p}$ spectrum contains a strong peak at $130.0 \mathrm{eV}$ corresponding to $\mathrm{Li}_{\mathrm{x}} \mathrm{PF}_{\mathrm{y}}$ species and the small peak at $136.0 \mathrm{eV}$ characteristic of $\mathrm{Li}_{\mathrm{x}} \mathrm{PF}_{\mathrm{y}} \mathrm{O}_{\mathrm{z}}$. The low concentration of $\mathrm{Li}_{\mathrm{x}} \mathrm{PF}_{\mathrm{y}} \mathrm{O}_{\mathrm{z}}$ most likely results from reaction of $\mathrm{Li}_{\mathrm{x}} \mathrm{PF}_{\mathrm{y}}$ with trace oxygen or moisture. The Li1s spectrum exhibits a broad peak around $56.3 \mathrm{eV}$ corresponding to combination of $\mathrm{LiF}_{\mathrm{Li}} \mathrm{Li}_{\mathrm{y}} \mathrm{PF}_{\mathrm{y}}$, and $\mathrm{Li}_{\mathrm{x}} \mathrm{PF}_{\mathrm{y}} \mathrm{O}_{\mathrm{z}}$. No residual $\mathrm{LiPF}_{6}(\mathrm{~F} 1 \mathrm{~s}, 687.6 \mathrm{eV} ; \mathrm{P} 2 \mathrm{p}$, $137.8 \mathrm{eV}$ ) is observed.

The F1s spectrum of the residual solids from the reduction of $\mathrm{LiBF}_{4}$ is dominated by a peak at $685 \mathrm{eV}$ characteristic of LiF. A shoulder is observed at 687.5 characteristic of $\mathrm{B}-\mathrm{F}$ species in $\mathrm{Li}_{\mathrm{x}} \mathrm{BF}_{\mathrm{y}}$ and residual $\mathrm{LiBF}_{4}$. The $\mathrm{B} 1 \mathrm{~s}$ spectrum is dominated by a peak at 190.5 $\mathrm{eV}$ corresponding to $\mathrm{Li}_{\mathrm{x}} \mathrm{BF}_{\mathrm{y}}$ species with a small peak at $195.7 \mathrm{eV}$ is characteristic of residual $\mathrm{LiBF}_{4}$. The Li1s spectrum exhibits a broad peak around $56.3 \mathrm{eV}$ corresponding to combination of $\mathrm{LiF}$, residual $\mathrm{LiBF}_{4}$ and $\mathrm{Li}_{\mathrm{x}} \mathrm{BF}_{\mathrm{y}}$.

\section{Discussion}

The reduction products of some of the most common electrolyte salts have been investigated via a combination of NMR, GC-MS, IRATR, and XPS. Upon reduction, all fluorine containing salts generate $\mathrm{LiF}$ and all oxalate containing salts generate lithium oxalate, in addition to other components which are dependent upon the structure of the salt. While the proposed equations provide estimates for the stoichiometries of the reactions as obtained from experimental results, due to the insolubility and hydrolytic instability of many of the reduction products quantitative analysis is difficult.

Reduction of $\mathrm{LiPF}_{6}$ yields $\mathrm{LiF}$ and $\mathrm{Li}_{\mathrm{x}} \mathrm{PF}_{\mathrm{y}}$ (Eq. 1). LiF is the predominant species observed by ${ }^{19} \mathrm{~F}$ NMR spectroscopy and F1s XPS. The primary phosphorous containing species observed in the P2p XPS spectrum is $\mathrm{Li}_{\mathrm{x}} \mathrm{PF}_{\mathrm{y}}$ with additional low concentrations of $\mathrm{Li}_{\mathrm{x}} \mathrm{PF}_{\mathrm{y}} \mathrm{O}_{\mathrm{z}}$. The presence of $\mathrm{Li}_{x} \mathrm{PF}_{\mathrm{y}} \mathrm{O}_{z}$ likely results from the reaction of $\mathrm{Li}_{\mathrm{x}} \mathrm{PF}_{\mathrm{y}}$ with trace water or oxygen (Eq. 2). Upon preparation of the samples for NMR analysis via dissolution in $\mathrm{D}_{2} \mathrm{O}$ the $\mathrm{Li}_{\mathrm{x}} \mathrm{PF}_{\mathrm{y}}$ is converted to $\mathrm{Li}_{\mathrm{x}} \mathrm{PO}_{\mathrm{y}} \mathrm{F}_{\mathrm{z}}$ via hydrolysis or oxidation. The reduction products of $\mathrm{LiBF}_{4}$ are very similar to the reduction products of $\mathrm{LiPF}_{6}$. The primary products observed by XPS are $\mathrm{LiF}$ and $\mathrm{Li}_{\mathrm{x}} \mathrm{BF}_{\mathrm{y}}$. Analysis of the $\mathrm{LiBF}_{4}$ reduction product by solution NMR spectroscopy reveals only $\mathrm{LiF}$ suggesting that $\mathrm{Li}_{\mathrm{x}} \mathrm{BF}_{\mathrm{y}}$ and the $\mathrm{Li}_{\mathrm{x}} \mathrm{BF}_{\mathrm{y}}$ hydrolysis or oxidation products are not soluble in $\mathrm{D}_{2} \mathrm{O}$. The observations are consistent with previous reports on the reduction products of $\mathrm{LiPF}_{6}$ and $\mathrm{LiBF}_{4}{ }^{28,29}$

$$
\begin{aligned}
& \mathrm{LiPF}_{6} \stackrel{4 \mathrm{e}^{-}}{4 \mathrm{Li}^{+}} 4 \mathrm{LiF}+\mathrm{Li}_{\mathrm{x}} \mathrm{PF}_{\mathrm{y}} \\
& \mathrm{Li}_{\mathrm{x}} \mathrm{PF}_{\mathrm{y}} \stackrel{[\mathrm{O}]}{\longrightarrow} \mathrm{Li}_{x} \mathrm{PO}_{\mathrm{y}} \mathrm{F}_{\mathrm{z}} \\
& \mathrm{LiBF}_{4} \stackrel{3 \mathrm{e}^{-}}{\stackrel{3 \mathrm{Li}^{+}}{\longrightarrow}} 3 \mathrm{LiF}+\mathrm{Li}_{\mathrm{x}} \mathrm{BF}_{\mathrm{y}}
\end{aligned}
$$

The primary reduction product of $\mathrm{LiBOB}$ is lithium oxalate although low concentrations of $\mathrm{Li}_{2} \mathrm{CO}_{3}$ are also observed by IR spectroscopy (Eq. 4). In addition, crosslinked oligomeric borates are observed consistent with previous reports. ${ }^{30}$ Reduction of LiDFOB results in the observation of very similar products, lithium oxalate, $\mathrm{Li}_{2} \mathrm{CO}_{3}$, and crosslinked oligomeric borates, along with $\mathrm{LiF}$ (Eq. 5). While $\mathrm{CO}_{2}$ is not observed by GC-MS analysis for either $\mathrm{LiBOB}$ or $\mathrm{LiDFOB}$, the presence of $\mathrm{Li}_{2} \mathrm{CO}_{3}$ in the solid residue likely results from $\mathrm{CO}_{2}$ reduction by the excess $\mathrm{Li}[\mathrm{Nap}]$, as previously reported. ${ }^{31}$

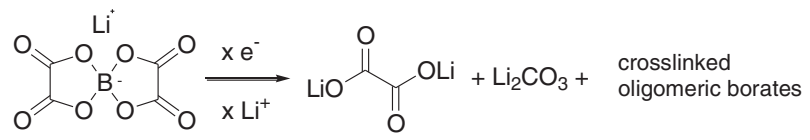

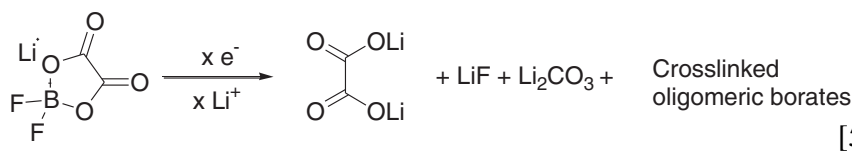

Reduction of LiTFSI results in the generation of two water soluble components, $\mathrm{LiF}$ and lithium bis[N-(trifluoromethylsulfonylimino)] trifluoromethanesulfonate as observed by NMR spectroscopy. Lithium bis[N-(trifluoromethylsulfonylimino)] trifluoromethanesulfonate is likely be formed through reductive cleavage of N-S bond, followed by insertion of the lithium imide into the $\mathrm{S}=\mathrm{O}$ bond (Eqs. 6-7). This mechanism is consistent with a combination of previously reported computational and experimental results. ${ }^{14,15,25}$ Reduction of LiTFSI requires a large excess of $\mathrm{Li}[\mathrm{Nap}](\sim 12)$ per equivalent 
of LiTFSI, consistent with further reduction of the intermediate product $\mathrm{LiSO}_{2} \mathrm{CF}_{3}$ to a combination of $\mathrm{LiF}, \mathrm{Li}_{2} \mathrm{~S}, \mathrm{Li}_{2} \mathrm{~S}_{2} \mathrm{O}_{4}, \mathrm{Li}_{2} \mathrm{SO}_{3}$, and $\mathrm{Li}_{3} \mathrm{~N}$ (Eq. 8). The presence of these compounds is supported by a previous reports on the reduction products of LiTFSI on negative electrode surfaces. ${ }^{14,32}$<smiles>O=S(=O)([Al-])[N-]S(=O)(=O)C(F)(F)F</smiles><smiles>O=S(=O)([AlH2])C(F)(F)F</smiles><smiles>NS(=O)(=O)C(F)(F)F</smiles><smiles>[Z17]N(S(=O)(=O)NS(=O)(=O)C(F)(F)F)S(=O)(=O)C(F)(F)F</smiles><smiles>O=S(=O)([AlH2])C(F)(F)F</smiles>

\section{Conclusions}

Reduction reactions of some of the most common lithium salts for lithium-ion battery electrolytes have been investigated. The reduction reactions of $\mathrm{LiPF}_{6}$ and $\mathrm{LiBF}_{4}$ are similar resulting in the generation of $\mathrm{LiF}$ and $\mathrm{Li}_{x} \mathrm{PF}_{\mathrm{y}}$ and $\mathrm{Li}_{\mathrm{x}} \mathrm{BF}_{\mathrm{y}}$, respectively. In carbonate based electrolytes, the $\mathrm{Li}_{\mathrm{x}} \mathrm{PF}_{\mathrm{y}}$ abstracts oxygen to generate $\mathrm{Li}_{\mathrm{x}} \mathrm{PF}_{\mathrm{y}} \mathrm{O}_{\mathrm{z}}$ consistent with previous reports of salt reduction products on anodes in lithium ion batteries. The reduction reactions of $\mathrm{LiBOB}$ and LiDFOB are also similar resulting in the generation of lithium oxalate, $\mathrm{Li}_{2} \mathrm{CO}_{3}$, and crosslinked oligoborates. In addition, $\mathrm{LiF}$ is observed as a reduction product of LiDFOB. Reduction of LiTFSI results in the generation of lithium bis[N-(trifluoromethylsulfonylimino)] trifluoromethanesulfonate along with $\mathrm{LiF}, \mathrm{Li}_{2} \mathrm{O}, \mathrm{Li}_{2} \mathrm{~S}, \mathrm{Li}_{2} \mathrm{~S}_{2} \mathrm{O}_{4}, \mathrm{Li}_{2} \mathrm{SO}_{3}$, and $\mathrm{Li}_{3} \mathrm{~N}$.

\section{Acknowledgment}

The authors gratefully acknowledge funding from Department of Energy Office of Basic Energy Sciences EPSCoR Implementation award (DE-SC0007074).

\section{ORCID}

Brett L. Lucht (D https://orcid.org/0000-0002-4660-0840

\section{References}

1. K. Xu, "Nonaqueous Liquid Electrolytes for Lithium-Based Rechargeable Batteries," Chem. Rev., 104, 4303 (2004).

2. D. Aurbach, B. Markovsky, A. Shechter, Y. Ein-Eli, and H. Cohen, "A Comparative Study of Synthetic Graphite and Li Electrodes in Electrolyte Solutions Based on Ethylene Carbonate-Dimethyl Carbonate Mixtures," J. Electrochem. Soc., 143, 3809 (1996).

3. Y. Ein-Eli, "A New Perspective on the Formation and Structure of the Solid Electrolyte Interface at the Graphite Anode of Li-Ion Cells," Electrochem. solid-state Lett., 2, 212 (1999).

4. G. V Zhuang and P. N. Ross, "Analysis of the Chemical Composition of the Passive Film on Li-Ion Battery Anodes Using Attentuated Total Reflection Infrared Spectroscopy," Electrochem. Solid-State Lett., 6, A136 (2003).

5. K. Xu, G. V Zhuang, J. L. Allen, U. Lee, S. S. Zhang, P. N. Ross, and T. R. Jow, "Syntheses and Characterization of Lithium Alkyl Mono-and Dicarbonates as Components of Surface Films in Li-Ion Batteries," J. Phys. Chem. B, 110, 7708 (2006).
6. L. Gireaud, S. Grugeon, S. Laruelle, S. Pilard, and J.-M. Tarascon, "Identification of Li Battery Electrolyte Degradation Products through Direct Synthesis and Characterization of Alkyl Carbonate Salts," J. Electrochem. Soc., 152, A850 (2005).

7. S. Laruelle, S. Pilard, P. Guenot, S. Grugeon, and J.-M. Tarascon, "Identification of Li-Based Electrolyte Degradation Products through DEI and ESI High-Resolution Mass Spectrometry," J. Electrochem. Soc., 151, A1202 (2004).

8. P. Verma, P. Maire, and P. Novák, "A Review of the Features and Analyses of the Solid Electrolyte Interphase in Li-Ion Batteries," Electrochim. Acta, 55, 6332 (2010).

9. E. Peled, "The Electrochemical Behavior of Alkali and Alkaline Earth Metals in Nonaqueous Battery Systems the Solid Electrolyte Interphase Model," J. Electrochem. Soc., 126, 2047 (1979)

10. D. Aurbach, "Review of Selected Electrode-Solution Interactions Which Determine the Performance of Li and Li Ion Batteries," J. Power Sources, 89, 206 (2000).

11. M. Winter, "The Solid Electrolyte Interphase-the Most Important and the Least Understood Solid Electrolyte in Rechargeable Li Batteries," Zeitschrift für Phys. Chemie Int. J. Res. Phys. Chem. Chem. Phys., 223, 1395 (2009).

12. M. Herstedt, D. P. Abraham, J. B. Kerr, and K. Edström, "X-Ray Photoelectron Spectroscopy of Negative Electrodes from High-Power Lithium-Ion Cells Showing Various Levels of Power Fade," Electrochim. Acta, 49, 5097 (2004).

13. G. V Zhuang, K. Xu, H. Yang, T. R. Jow, and P. N. Ross, "Lithium Ethylene Dicarbonate Identified as the Primary Product of Chemical and Electrochemical Reduction of EC in 1.2 M LiPF6/EC: EMC Electrolyte," J. Phys. Chem. B, 109, 17567 (2005).

14. D. Aurbach, I. Weissman, A. Schechter, and H. Cohen, "X-Ray Photoelectron Spectroscopy Studies of Lithium Surfaces Prepared in Several Important Electrolyte Solutions. A Comparison with Previous Studies by Fourier Transform Infrared Spectroscopy," Langmuir, 12, 3991 (1996).

15. P. C. Howlett, E. I. Izgorodina, M. Forsyth, and D. R. MacFarlane, "Electrochemistry at Negative Potentials in Bis (Trifluoromethanesulfonyl) Amide Ionic Liquids," Zeitschrift für Phys. Chemie, 220, 1483 (2006)

16. G. Yan, X. Li, Z. Wang, H. Guo, W. Peng, and Q. Hu, "Lithium Difluoro (Oxalato) Borate as an Additive to Suppress the Aluminum Corrosion in Lithium Bis (Fluorosulfony) Imide-Based Nonaqueous Carbonate Electrolyte," J. Solid State Electrochem. 20, 507 (2016).

17. M. Gauthier, T. J. Carney, A. Grimaud, L. Giordano, N. Pour, H.-H. Chang, D. P. Fenning, S. F. Lux, O. Paschos, C. ; Bauer et al., "Electrode-Electrolyte Interface in Li-Ion Batteries: Current Understanding and New Insights," J. Phys. Chem. Lett., 6, 4653 (2015)

18. G. V Zhuang, K. Xu, T. R. Jow, and P. N. Ross, "Study of SEI Layer Formed on Graphite Anodes in PC/LiBOB Electrolyte Using IR Spectroscopy," Electrochem. solid-state Lett., 7, A224 (2004).

19. M. Xu, L. Zhou, Y. Dong, Y. Chen, A. Garsuch, and B. L. Lucht, "Improving the Performance of graphite/LiNi0. 5Mn1. 5O4 Cells at High Voltage and Elevated Temperature with Added Lithium Bis (Oxalato) Borate (LiBOB)," J. Electrochem. Soc., 160, A2005 (2013).

20. M. Nie, D. Chalasani, D. P. Abraham, Y. Chen, A. Bose, and B. L. Lucht, "Lithium Ion Battery Graphite Solid Electrolyte Interphase Revealed by Microscopy and Spectroscopy," J. Phys. Chem. C, 117, 1257 (2013).

21. M. Nie and B. L. Lucht, "Role of Lithium Salt on Solid Electrolyte Interface (SEI) Formation and Structure in Lithium Ion Batteries," J. Electrochem. Soc., 161, A1001 (2014).

22. D. M. Seo, D. Chalasani, B. S. Parimalam, R. Kadam, M. Nie, and B. L. Lucht, "Reduction Reactions of Carbonate Solvents for Lithium Ion Batteries," ECS Electrochem. Lett., 3, A91 (2014).

23. N. G. Connelly and W. E. Geiger, "Chemical Redox Agents for Organometallic Chemistry," Chem. Rev., 96, 877 (1996)

24. C. L. Campion, W. Li, and B. L. Lucht, "Thermal Decomposition of LiPF6-Based Electrolytes for Lithium-Ion Batteries," J. Electrochem. Soc., 152, A2327 (2005).

25. R. Y. Garlyauskayte, A. N. Chernega, C. Michot, M. Armand, Y. L. Yagupolskii, and L. M. Yagupolskii, "Synthesis of New Organic Super acids N(Trifluoromethylsulfonyl) Imino Derivatives of Trifluoromethanesulfonic Acid and Bis (Trifluoromethylsulfonyl) Imide," Org. Biomol. Chem., 3, 2239 (2005).

26. I. A. Shkrob, Y. Zhu, T. W. Marin, and D. P. Abraham, "Mechanistic Insight into the Protective Action of Bis (Oxalato) Borate and Difluoro (Oxalate) Borate Anions in Li-Ion Batteries," J. Phys. Chem. C, 117, 23750 (2013).

27. K. Xu, U. Lee, S. Zhang, M. Wood, and T. R. Jow, "Chemical Analysis of Graphite/electrolyte Interface Formed in LiBOB-Based Electrolytes," Electrochem. Solid-State Lett., 6, A144 (2003).

28. K. Kanamura, H. Tamura, S. Shiraishi, and Z. Takehara, "XPS Analysis of Lithium Surfaces Following Immersion in Various Solvents Containing LiBF4," J. Electrochem. Soc., 142, 340 (1995).

29. A. M. Andersson, M. Herstedt, A. G. Bishop, and K. Edström, "The Influence of Lithium Salt on the Interfacial Reactions Controlling the Thermal Stability of Graphite Anodes," Electrochim. Acta, 47, 1885 (2002).

30. K. Xu, U. Lee, S. Zhang, M. Wood, and T. R. Jow, "Chemical Analysis of Graphite/electrolyte Interface Formed in LiBOB-Based Electrolytes," Electrochem. Solid-State Lett., 6, A144 (2003).

31. A. L. Michan, B. S. Parimalam, M. Leskes, R. N. Kerber, T. Yoon, C. P. Grey, and B. L. Lucht, "Fluoroethylene Carbonate and Vinylene Carbonate Reduction: Understanding Lithium-Ion Battery Electrolyte Additives and Solid Electrolyte Interphase Formation," Chem. Mater, 28, 8149 (2016).

32. C. Xu, B. Sun, T. Gustafsson, K. Edström, D. Brandell, and M. Hahlin, "Interface Layer Formation in Solid Polymer Electrolyte Lithium Batteries: An XPS Study," J. Mater. Chem. A, 2, 7256 (2014). 